\title{
Anxiety and depression during pregnancy in
} women attending clinics in a University Hospital in Eastern province of Saudi Arabia: prevalence and associated factors

This article was published in the following Dove Press journal:

International Journal of Women's Health

\author{
Abdullah H Alqahtani ${ }^{1}$ \\ Kholoud Al Khedair ${ }^{2}$ \\ Reem Al-Jeheiman ${ }^{2}$ \\ Haifa A Al-Turki \\ Nourah H Al Qahtani ${ }^{2}$ \\ 'Department of Psychiatry, College \\ of Medicine, Imam Abdulrahman \\ Bin Faisal University, Dammam, \\ ${ }^{2}$ Department of Obstetrics and \\ Gynaecology, College of Medicine, \\ Imam Abdulrahman Bin Faisal \\ University, Dammam, Saudi Arabia
}

\begin{abstract}
Background: Anxiety and depression during the antenatal period is a growing problem with major effects on the mother, the developing fetus, and the neonate.

Objectives: To assess the prevalence of anxiety and depression during pregnancy in women attending the hospital for antenatal care and assess the associated factors.

Methods: This is a prospective cohort study conducted in the University Hospital of Imam Abdulrahman Bin Faisal University. Anxiety was evaluated using State Trait Anxiety Inventory. Depression was assessed using Edinburgh Postnatal Depression Scale (EPDS).

Results: Complete data were available for 575 women. The mean EPDS score was 10.5 (SD 5.5). The prevalence of depression was $26.8 \%$. The mean state-anxiety score was 38.4 (SD 11.4) and mean trait-anxiety score was 38.2 (SD 9.5). The prevalence of anxiety using state-anxiety scale was $23.6 \%$, while using the trait scale it was $23.9 \%$. The risk is higher among unemployed women with history of miscarriage and unplanned pregnancy.

Conclusion: Anxiety and depression are common during pregnancy.

Keywords: anxiety, depression, pregnancy
\end{abstract}

\section{Introduction}

Traditionally, research on psychological morbidity in the perinatal period has focused on postpartum depression. However, in recent years, increased attention has been paid to the antenatal period. Accumulating evidence indicates that many women experience psychological distress during pregnancy. For example, a large population-based study in Sweden has estimated that $14 \%$ of pregnant women had one or more psychiatric disorder. ${ }^{1}$ Mood disorders are common with prevalence rates for depression reported to be $7.4 \%$ in the first trimester, $12.8 \%$ in the second trimester, and $12.0 \%$ in the third trimester. ${ }^{2}$ The body of literature on psychological morbidity during pregnancy comes from Western countries with relatively few studies from other regions of the world. Nasreen et al studied a large sample of pregnant women in Bangladesh and found rates of antenatal depression and anxiety to be $18 \%$ and $29 \%$, respectively. ${ }^{3}$ In Pakistan, a study has established that $18 \%$ of pregnant women were anxious and/or depressed. ${ }^{4}$ A recent study in neighboring Oman has estimated a prevalence rate of antenatal depression of $24.3 \% .^{5}$ In this study, antenatal depression was associated with unplanned pregnancies, family history of depression, and marital discord. The presence of psychiatric disorders during pregnancy imposes a significant burden on women 
and has the potential to adversely affect obstetric, fetal, and neonatal outcomes. ${ }^{6}$ Evidence for this comes from several studies including meta-analytic reviews that have established that anxiety and depression during pregnancy are associated with preterm birth and low birth weight. ${ }^{7-9}$

Little is known about the epidemiology of psychiatric disorders during pregnancy in Saudi Arabia with prior research focusing on the postpartum period. ${ }^{10}$ In this study, we sought to assess the prevalence of anxiety and depression during pregnancy in women attending antenatal clinics in a university hospital in the Eastern region of Saudi Arabia and to find if there are associated factors with anxiety and depression.

\section{Materials and methods Setting}

The study was conducted at King Fahd University Hospital, Imam Abdulrahman Bin Faisal University. This is the main provider for secondary care services to the residents of the city of Al-Khobar in the Eastern province of Saudi Arabia with $\sim 1,800-2,500$ births per year. King Fahd Hospital is also considered as a tertiary referral center for high-risk pregnancies for the entire Eastern province.

\section{Participants}

Subjects were pregnant women attending the outpatient department for antenatal care. Inclusion criteria included age 18-45 and ability to speak Arabic or English. The exclusion criteria were refusal to give consent and women who did not speak Arabic or English, as the questionnaires were available in these two languages.

\section{Measurements}

Sociodemographic and clinical data were collected using a questionnaire sheet. Anxiety was measured by the State Trait Anxiety Inventory (STAI), ${ }^{11}$ which is the most widely used measure of anxiety during pregnancy. ${ }^{12}$ Permission to use the STAI was obtained from Mind Garden publishing Inc. on November 30, 2013. The STAI is a self-administered questionnaire that is composed of two scales: state-anxiety scale that measures current anxiety and trait-anxiety scale that measures general feelings of anxiety. The Arabic translation of the STAI was adapted to the Saudi dialect by consensus meeting of consultant psychiatrists and clinical psychologists with extensive knowledge of the local culture. In accordance with prior research, ${ }^{13-15}$ the 75 th percentile (state $\geq 46$; trait $\geq 45$ ) was used to determine the cutoff point for state- and trait-anxiety scales. This test has been used extensively in clinical research and also in clinical practice to assess anxiety. The test has two separate self-report scales measuring state and trait anxiety. The state-anxiety scale (STAI form Y-1) evaluates how the participant feels "right now at this moment". The trait-anxiety scale (STAI Form Y-2) assesses how the participant feels in general. Both scales consist of 20 statements.

Depression was measured by the Edinburgh Postnatal Depression Scale (EPDS). ${ }^{16}$ This is a 10 -item scale with each item scored from 0 to 3 (minimum score 0 , maximum 30 ). While the EPDS was primarily designed to detect postnatal depression, it has been shown to be an accurate tool for measuring depression during pregnancy. ${ }^{17}$ We used the Arabic version of the EPDS that has been previously validated in a sample of Emirati women. ${ }^{18}$ A cutoff score of $\geq 14$ was considered positive for depression.

\section{Statistical analysis}

Data from the three assessment tools were given codes and organized in data Excel sheet. Descriptive data were presented as numbers and percentages. Online calculator was used for calculation (http://www.socscistatistics.com). Odds ratio and confidence interval were calculated using online calculators at http://www.vassarstats.net. A $p$-value of $\leq 0.05$ was chosen as the level of statistical significance.

\section{Results}

During the study period, January 2015 to February 2016, 679 women were recruited to the study. Seventy-five women refused to participate in the study because they did not have the time or were not interested. Twenty-nine participants did not fill all the forms and were excluded. Those who had filled all the questions as well as the sociodemographic data were included ( 575 women). The characteristics of the study subjects are shown in Table 1 . The majority (77.7\%) of our study subjects were Saudi nationals. Sixty percent of the study subjects had a university degree and over half of all participants were homemakers. Twenty-nine percent were pregnant for the first time with 58\% stating that it was a planned pregnancy. Forty-seven percent of women were in the third trimester with a mean gestational age of 29.2 (SD 8.3). Over one third of women in our study had a history of miscarriage.

\section{Prevalence of anxiety and depression during pregnancy}

The mean EPDS score was 10.5 (SD 5.5). The prevalence of depression was $26.8 \%$. The mean state-anxiety score was 38.4 (SD 11.4) and mean trait-anxiety score was 38.2 (SD 9.5). 
Table I Characteristics of the participants

\begin{tabular}{|c|c|}
\hline Women's characteristics & $\mathbf{N}(\%)$ \\
\hline \multicolumn{2}{|l|}{ Age, years } \\
\hline $18-20$ & $22(3.8)$ \\
\hline $21-30$ & $300(52.2)$ \\
\hline $31-40$ & $230(40)$ \\
\hline $4 \mid-45$ & $23(4)$ \\
\hline \multicolumn{2}{|l|}{ Trimester } \\
\hline First & $90(15.7)$ \\
\hline Second & $214(37.2)$ \\
\hline Third & $27 I(47.1)$ \\
\hline \multicolumn{2}{|l|}{ Gravidity } \\
\hline I & $168(29.2)$ \\
\hline $2-17$ & $407(70.8)$ \\
\hline \multicolumn{2}{|l|}{ Number of abortions } \\
\hline 0 & $37 \mid(64.5)$ \\
\hline $1-13$ & $204(35.5)$ \\
\hline \multicolumn{2}{|l|}{ Education in years } \\
\hline$<6$ & $32(5.7)$ \\
\hline $6-12$ & $165(28.7)$ \\
\hline$>12$ & $349(60.7)$ \\
\hline Unknown & $28(4.9)$ \\
\hline \multicolumn{2}{|l|}{ Employment } \\
\hline Employed & $196(34.1)$ \\
\hline Non-employed & $316(54.9)$ \\
\hline Student & $63(\mathrm{II})$ \\
\hline \multicolumn{2}{|l|}{ Income in Saudi Riyals } \\
\hline$<5,000$ & $83(14.4)$ \\
\hline $5,000-10,000$ & $216(37.6)$ \\
\hline$>10,000$ & $275(47.8)$ \\
\hline \multicolumn{2}{|l|}{ Medical problems } \\
\hline Present & I5I (26.3) \\
\hline Absent & $424(73.7)$ \\
\hline \multicolumn{2}{|l|}{ Planned pregnancy } \\
\hline Yes & $332(58)$ \\
\hline No & $243(42)$ \\
\hline \multicolumn{2}{|c|}{ Negative impact of pregnancy } \\
\hline Yes & $287(49.9)$ \\
\hline No & $288(50.1)$ \\
\hline \multicolumn{2}{|l|}{ Living arrangement } \\
\hline With spouse & $468(81.4)$ \\
\hline Without spouse & $107(18.6)$ \\
\hline \multicolumn{2}{|l|}{ Housing type } \\
\hline Owned & $182(31.7)$ \\
\hline Rented & $393(68.3)$ \\
\hline \multicolumn{2}{|l|}{ Nationality } \\
\hline Saudi & 447 (77.7) \\
\hline Non-Saudi & $128(22.3)$ \\
\hline
\end{tabular}

The prevalence of anxiety using state-anxiety scale was $23.6 \%$, while using the trait scale it was $23.9 \%$.

\section{Association with sociodemographic and clinical factors}

Antenatal depression and anxiety were not associated with gestational age, maternal age, number of pregnancies, living arrangement, family income, housing type, nationality, or presence of medical problems (Tables 2-4).

History of previous miscarriages increased the odds ratio of depression ( $p$-value 0.00001). Non-employed women were more likely to have depression compared to employed women and students ( $p$-value 0.03). Another significant finding was the higher depression rate among women who had unplanned pregnancy ( $p$-value 0.00001) and thought that the pregnancy would negatively impact their life and work ( $p$-value 0.0002).

Anxiety-trait score was also higher among women with recurrent miscarriage ( $p$-value 0.004). Students and employed women had a lower anxiety-trait score compared with unemployed women ( $p$-value 0.003). Unplanned pregnancy was associated with higher score ( $p$-value 0.00001).

Anxiety-state score was higher among women who had unplanned pregnancy and thought that their pregnancy will have negative impact on their life ( $p$-value 0.00001 for both).

\section{Discussion}

The past two decades have witnessed increased interest in promoting awareness, diagnosis, treatment, and prevention of mental health problems. In 2001, the World Health Organization published its annual world health report under the title "mental health: new understanding new hope". ${ }^{19}$ This signaled a focus on efforts to draw attention to this neglected field. For instance, unipolar depressive disorders ranked fourth among the top five leading contributors to the global burden of disease in $2000 .{ }^{20}$ Moreover, projections suggest that by 2020, unipolar depression will be the second most common cause of morbidity in the world. This is as measured by disability-adjusted life years. ${ }^{21}$

Anxiety and depression contribute to the increased burden of health risks to the mothers and their babies. Furthermore, pregnancy is considered to be "a period of psychological change and challenge". ${ }^{22}$ Therefore, it is not unusual for pregnant women to experience anxiety about their physical health, the development and health of the baby, and fears of inability to cope. ${ }^{23}$ However, such normal emotional changes are to be distinguished from psychiatric disorders; of these, depression and anxiety are among the most common disorders to be reported. ${ }^{6,23}$ Untreated perinatal mental disorders may have severe psychiatric and obstetric short- and long-term consequences, for the woman, her family, and mostly for the newborn baby. As such, there is a mixed literature on the association between psychological morbidity during pregnancy and adverse pregnancy outcomes. For example, a study by Andersson has 
Table 2 Characteristics of the participants, total number and percentage of depression (D), odds ratio (OR), $95 \% \mathrm{Cl}, \mathrm{p}$-values, and order of entrance in the logistic regression model

\begin{tabular}{|c|c|c|c|c|c|}
\hline $\begin{array}{l}\text { Women's } \\
\text { characteristics }\end{array}$ & $\mathbf{N}$ & D cases (\%) & OR $(95 \% \mathrm{Cl})$ & $p$-value & $\begin{array}{l}\text { Entrance } \\
\text { order }\end{array}$ \\
\hline \multicolumn{4}{|l|}{ Age, years } & 0.097 & \\
\hline $18-20$ & 22 & $3(13.6)$ & I & & \\
\hline $21-30$ & 300 & $70(23.3)$ & $1.9(0.55-6.7 I)$ & & \\
\hline $31-40$ & 230 & $72(31.3)$ & $2.88(0.83-10.06)$ & & \\
\hline $4 I-45$ & 23 & $7(30.4)$ & $2.77(0.6 \mathrm{I}-12.5)$ & & \\
\hline \multicolumn{4}{|l|}{ Trimester } & 0.13 & \\
\hline First & 90 & $16(17.8)$ & 1 & & \\
\hline Second & 214 & $61(28.6)$ & $1.84(0.99-3.42)$ & & \\
\hline Third & 271 & $74(27.3)$ & $1.73(0.95-3.17)$ & & \\
\hline \multicolumn{4}{|l|}{ Gravidity } & 0.21 & \\
\hline I & 168 & $37(22)$ & I & & \\
\hline $2-17$ & 407 & $110(27)$ & $1.31(0.86-2.00)$ & & \\
\hline \multicolumn{4}{|c|}{ Number of abortions } & 0.00001 & \\
\hline 0 & 371 & $95(25.6)$ & I & & I \\
\hline $1-13$ & 204 & $98(48)$ & $2.69(1.87-3.85)$ & & \\
\hline \multicolumn{4}{|c|}{ Education in years } & 0.03 & \\
\hline$<6$ & 32 & $7(2 \mathrm{I})$ & I & & 5 \\
\hline $6-12$ & 165 & $58(35.2)$ & $1.94(0.79-4.75)$ & & \\
\hline$>12$ & 349 & $81(23.2)$ & $1.08(0.45-2.59)$ & & \\
\hline Unknown & 28 & $7(25)$ & $1.19(0.36-3.94)$ & & \\
\hline \multicolumn{4}{|l|}{ Employment } & 0.03 & \\
\hline Employed & 196 & $49(25)$ & I & & 4 \\
\hline Non-employed & 316 & $94(29.7)$ & $1.27(0.85-1.90)$ & & \\
\hline Student & 63 & $9(14.3)$ & $0.5(0.23-1.09)$ & & \\
\hline \multicolumn{4}{|c|}{ Income in Saudi Riyals } & 0.9 & \\
\hline$<5,000$ & 83 & $23(27.7)$ & I & & \\
\hline $5,000-10,000$ & 216 & $58(26.9)$ & $0.96(0.54-1.68)$ & & \\
\hline$>10,000$ & 275 & $70(25.5)$ & $0.89(0.5 \mathrm{I}-\mathrm{I} .54)$ & & \\
\hline \multicolumn{4}{|c|}{ Medical problems } & 0.15 & \\
\hline Present & $|5|$ & $47(3 \mathrm{I})$ & I & & \\
\hline Absent & 424 & $106(25)$ & $0.74(0.49-1.11)$ & & \\
\hline \multicolumn{4}{|c|}{ Planned pregnancy } & 0.00001 & \\
\hline Yes & 332 & $64(19)$ & 1 & & 2 \\
\hline No & 243 & $89(36.8)$ & $2.42(1.66-3.53)$ & & \\
\hline \multicolumn{4}{|c|}{ Negative impact of pregnancy } & 0.0002 & \\
\hline Yes & 287 & $91(31.7)$ & I & & 3 \\
\hline No & 288 & $52(18)$ & $0.47(0.32-0.70)$ & & \\
\hline \multicolumn{4}{|c|}{ Living arrangement } & 0.65 & \\
\hline With spouse & 468 & $|2|(26)$ & I & & \\
\hline Without spouse & 107 & $30(28)$ & I.I (0.70-I.78) & & \\
\hline \multicolumn{4}{|l|}{ Housing type } & 0.9 & \\
\hline Owned & 182 & 49 (26.9) & I & & \\
\hline Rented & 393 & $104(26.5)$ & $0.98(0.66-1.45)$ & & \\
\hline \multicolumn{4}{|l|}{ Nationality } & 0.17 & \\
\hline Saudi & 447 & $125(28)$ & I & & \\
\hline Non-Saudi & 128 & $28(22)$ & $0.72(0.45-1.15)$ & & \\
\hline
\end{tabular}

found no association between antenatal depression and anxiety and neonatal outcome. ${ }^{24}$ Conversely, a recent meta-analysis has shown a modest association between depression during pregnancy and low birth weight and preterm birth. ${ }^{\text {? }}$

During the last two decades, the main emphasis of research has been concerned about women experiencing symptoms of anxiety and depression in the postpartum period. Many other studies addressed the clinical management of postpartum depression or the use of antidepressant drugs on the mother and their fetuses. ${ }^{25}$

The concept of pregnancy anxiety has been introduced recently. ${ }^{26}$ Now, pregnancy anxiety is recognized as an 
Table 3 Characteristics of the participants, total number and percentage of trait anxiety (AT), odds ratio (OR), $95 \% \mathrm{Cl}, \mathrm{p}$-values, and order of entrance in the logistic regression model

\begin{tabular}{|c|c|c|c|c|c|}
\hline $\begin{array}{l}\text { Women's } \\
\text { characteristics }\end{array}$ & $\mathbf{N}$ & AT cases (\%) & OR $(95 \% \mathrm{Cl})$ & $p$-value & $\begin{array}{l}\text { Entrance } \\
\text { order }\end{array}$ \\
\hline \multicolumn{4}{|l|}{ Age, years } & 0.66 & \\
\hline $18-20$ & 22 & $6(27.3)$ & I & & \\
\hline $21-30$ & 300 & $105(35)$ & $\mathrm{I} .44(0.55-3.78)$ & & \\
\hline $31-40$ & 230 & 89 (38.7) & $1.68(0.63-4.46)$ & & \\
\hline $4 I-45$ & 23 & $8(34.8)$ & $1.42(0.40-5.07)$ & & \\
\hline \multicolumn{4}{|l|}{ Trimester } & 0.009 & \\
\hline First & 90 & $21(23.3)$ & 1 & & 2 \\
\hline Second & 214 & $89(4 I)$ & $2.36(1.35-4.13)$ & & \\
\hline Third & 271 & $98(36)$ & $1.86(1.08-3.22)$ & & \\
\hline \multicolumn{4}{|l|}{ Gravidity } & 0.004 & \\
\hline I & 168 & $46(27.4)$ & I & & 4 \\
\hline $2-17$ & 407 & $163(40)$ & $1.77(1.20-2.62)$ & & \\
\hline \multicolumn{4}{|c|}{ Number of abortions } & 0.97 & \\
\hline 0 & 371 & $132(35.6)$ & I & & \\
\hline $1-13$ & 204 & $77(37.7)$ & $1.01(0.70-1.44)$ & & \\
\hline \multicolumn{4}{|c|}{ Education in years } & 0.13 & \\
\hline$<6$ & 32 & $10(31.3)$ & I & & \\
\hline $6-12$ & 165 & $72(43.6)$ & $1.7(0.76-3.80)$ & & \\
\hline$>12$ & 349 & $116(33.2)$ & I.I (0.50-2.39) & & \\
\hline Unknown & 28 & II (39.3) & $1.42(0.49-4.12)$ & & \\
\hline \multicolumn{4}{|l|}{ Employment } & 0.003 & \\
\hline Employed & 196 & $65(33.2)$ & I & & 3 \\
\hline Non-employed & 316 & $135(42.7)$ & $1.5(1.04-2.18)$ & & \\
\hline Student & 63 & $14(22.2)$ & $0.58(0.3-1.12)$ & & \\
\hline \multicolumn{4}{|c|}{ Income in Saudi Riyals } & 0.07 & \\
\hline$<5,000$ & 83 & $33(39.8)$ & I & & \\
\hline $5,000-10,000$ & 216 & $88(40.7)$ & $1.04(0.62-1.75)$ & & \\
\hline$>10,000$ & 275 & $86(31.3)$ & $0.69(0.4 I-1.15)$ & & \\
\hline \multicolumn{4}{|c|}{ Medical problems } & 0.84 & \\
\hline Present & 151 & $56(37)$ & I & & \\
\hline Absent & 424 & $153(36)$ & $0.96(0.65-1.43)$ & & \\
\hline \multicolumn{4}{|c|}{ Planned pregnancy } & 0.00001 & \\
\hline Yes & 332 & I0I (30.4) & I & & I \\
\hline No & 243 & $108(44.6)$ & $1.84(1.31-2.60)$ & & \\
\hline \multicolumn{4}{|c|}{ Negative impact of pregnancy } & 0.11 & \\
\hline Yes & 287 & $115(40.1)$ & I & & \\
\hline No & 288 & $97(33.7)$ & $0.76(0.54-1.07)$ & & \\
\hline \multicolumn{4}{|c|}{ Living arrangement } & 0.23 & \\
\hline With spouse & 468 & $182(39)$ & I & & \\
\hline Without spouse & 107 & 35 (32.7) & $0.76(0.49-1.19)$ & & \\
\hline \multicolumn{4}{|l|}{ Housing type } & 0.29 & \\
\hline Owned & 182 & $76(4 \mid .8)$ & I & & \\
\hline Rented & 393 & $146(37.2)$ & $0.82(0.58-1.18)$ & & \\
\hline \multicolumn{4}{|l|}{ Nationality } & 0.49 & \\
\hline Saudi & 447 & $161(36)$ & I & & \\
\hline Non-Saudi & 128 & $50(39.4)$ & $1.15(0.77-1.73)$ & & \\
\hline
\end{tabular}

independent risk factor for spontaneous preterm birth. There is a great emphasis also on the multilevel mechanism of the negative affective state (anxiety and depression) on neonatal birth weight. Birth weight has been linked to adverse outcome in the neonatal, childhood, and adult life. This is known as Baker hypothesis, which states that many adult diseases (coronary artery disease, diabetes, hypertension, and stroke) have fetal origin. The most widely accepted mechanism for this effect is fetal programming by nutritional stimuli or excess fetal glucocorticoid exposure. ${ }^{27}$ Hormonal challenge tests, such as the dexamethasone/ corticotropin-releasing hormone test, have revealed elevated 
Table 4 Characteristics of the participants, total number and percentage of state anxiety (AS), odds ratio (OR), $95 \% \mathrm{Cl}, \mathrm{p}$-values, and order of entrance in the logistic regression model

\begin{tabular}{|c|c|c|c|c|c|}
\hline $\begin{array}{l}\text { Women's } \\
\text { characteristics }\end{array}$ & $\mathbf{N}$ & AS cases (\%) & OR $(95 \% \mathrm{Cl})$ & $p$-value & $\begin{array}{l}\text { Entrance } \\
\text { order }\end{array}$ \\
\hline \multicolumn{4}{|l|}{ Age, years } & 0.89 & \\
\hline $18-20$ & 22 & $9(4 I)$ & 1 & & \\
\hline $21-30$ & 300 & $114(38)$ & $0.89(0.37-2.14)$ & & \\
\hline $31-40$ & 230 & $95(4 I .3)$ & $1.02(0.42-2.47)$ & & \\
\hline $41-45$ & 23 & 9 (39) & $0.93(0.28-3.06)$ & & \\
\hline \multicolumn{4}{|l|}{ Trimester } & 0.58 & \\
\hline First & 90 & $31(34.4)$ & I & & \\
\hline Second & 214 & $87(40.8)$ & I.3। (0.79-2.2) & & \\
\hline Third & $27 \mid$ & $107(39.5)$ & $1.24(0.75-2.04)$ & & \\
\hline \multicolumn{4}{|l|}{ Gravidity } & 0.8 & \\
\hline I & 168 & $65(38.7)$ & I & & \\
\hline $2-17$ & 407 & $162(39.8)$ & $\mathrm{I} .05(0.72-I .5 \mathrm{I})$ & & \\
\hline \multicolumn{4}{|c|}{ Number of abortions } & 0.38 & \\
\hline 0 & 371 & $152(4 \mid)$ & I & & \\
\hline $1-13$ & 204 & $76(37.3)$ & $0.86(0.60-1.21)$ & & \\
\hline \multicolumn{4}{|c|}{ Education in years } & 0.39 & \\
\hline$<6$ & 32 & $9(28)$ & I & & \\
\hline $6-12$ & 165 & $70(42.4)$ & $1.88(0.82-4.32)$ & & \\
\hline$>12$ & 349 & $135(38.7)$ & $1.61(0.72-3.59)$ & & \\
\hline Unknown & 28 & $13(46.4)$ & $2.21(0.76-6.46)$ & & \\
\hline \multicolumn{4}{|l|}{ Employment } & 0.04 & \\
\hline Employed & 196 & $85(43)$ & I & & \\
\hline Non-employed & 316 & $125(40)$ & $0.85(0.60-1.22)$ & & \\
\hline Student & 63 & $16(25.4)$ & $0.44(0.24-0.84)$ & & \\
\hline \multicolumn{4}{|c|}{ Income in Saudi Riyals } & 0.91 & \\
\hline$<5,000$ & 83 & $31(37)$ & I & & \\
\hline $5,000-10,000$ & 216 & $85(39)$ & $1.09(0.65-1.83)$ & & \\
\hline$>10,000$ & 275 & $110(40)$ & $1.12(0.67-1.85)$ & & \\
\hline \multicolumn{4}{|c|}{ Medical problems } & 0.8 & \\
\hline Present & 151 & $61(40)$ & I & & \\
\hline Absent & 424 & $166(39)$ & $0.95(0.65-1.39)$ & & \\
\hline \multicolumn{4}{|c|}{ Planned pregnancy } & 0.00001 & \\
\hline Yes & 332 & $103(3 \mid)$ & I & & 2 \\
\hline No & 243 & $124(5 \mid)$ & $2.34(1.66-3.29)$ & & \\
\hline \multicolumn{4}{|c|}{ Negative impact of pregnancy } & 0.00001 & \\
\hline Yes & 287 & $129(45)$ & I & & I \\
\hline No & 288 & $98(34)$ & $0.33(0.23-0.48)$ & & \\
\hline \multicolumn{4}{|c|}{ Living arrangement } & 0.61 & \\
\hline With spouse & 468 & $187(40)$ & I & & \\
\hline Without spouse & 107 & $40(37.4)$ & $0.89(0.58-1.38)$ & & \\
\hline \multicolumn{4}{|l|}{ Housing type } & 0.45 & \\
\hline Owned & 182 & $76(4 \mid .6)$ & I & & \\
\hline Rented & 393 & 151 (38.4) & $0.87(0.6 \mathrm{I}-\mathrm{I} .24)$ & & \\
\hline \multicolumn{4}{|l|}{ Nationality } & 0.58 & \\
\hline Saudi & 447 & $|8|(40.5)$ & I & & \\
\hline Non-Saudi & 128 & $48(37.8)$ & $0.89(0.59-1.34)$ & & \\
\hline
\end{tabular}

hypothalamic-pituitary-adrenal activity (hypercortisolism) in at least a portion of women with depression. Glucocorticoids readily cross the placental barrier, and this may play a role in the development of growth restriction in women with negative affective states.
Little is known about the epidemiology of psychiatric disorders during pregnancy in Saudi Arabia. On the other hand, many countries have well established prevalence of these conditions. ${ }^{28-33}$ Prior research in Saudi Arabia has focused on the postpartum period, ${ }^{10}$ and to the best of our 
knowledge the present study is the first to examine this issue. The prevalence of depression varies from $5 \%$ to $36 \%$ in various studies. The EPDS has to be interpreted carefully as it is only a screening test. If only women scoring more than 14 on EPDS were considered as likely to have depression, then the prevalence in this study is $26.8 \%$.

The high prevalence of state and trait anxiety in this study is consistent with other studies. ${ }^{22}$ This is mainly because pregnancy is considered to be a period of psychological change and challenge. The other reason for the high prevalence is that many of the somatic manifestations (for example, feeling tired) of anxiety are sometimes part of the normal physiological changes of pregnancy. This is again emphasizing the screening nature of the STAI tests. It should not replace the proper psychiatric evaluation for definitive diagnosis.

Limitations of this study include the absence of a proper psychiatric evaluation for those women who scored high (positive) in the study.

Based on this study, it is recommended to perform larger study with further psychiatric evaluation following the positive screen test for anxiety and depression to assess the actual prevalence of anxiety and depression in Saudi Arabia.

\section{Ethical approval and informed consent}

Ethical approval for the study was obtained from the Deanship of Scientific Research, Imam Abdulrahman Bin Faisal University (ethical approval number 2013190), after complete description of the study and the expected benefits from the study. The study protocol was reviewed by the Institutional Review Board of Imam Abdulrahman Bin Faisal University. All subjects signed an informed consent before taking part in the study.

\section{Data sharing statement}

The full dataset has not been stored in a public repository because it contains identifiers that may lead to identification of individual participants. The data presented in the article will not lead to identification of women because it only contains summarized results. The full dataset is freely available upon a reasonable written request to the corresponding author.

\section{Acknowledgments}

We thank all the ladies who shared the most intimate and private details of their life with us to improve our understanding of this problem. Our sincere thanks go to all our medical students and student interns who spent a great deal of their valuable time to help us collect the data. A poster abstract was sent to the Royal College of Obstetricians and Gynecologists Congress, June 20-22, 2016, UK.

\section{Author contributions}

AA and NHQ conceived and designed the study. All authors implemented the study and supervised data collection. NHQ was responsible for database management and analysis. AA and NHQ supervised the analysis process, interpreted the findings, and drafted the manuscript. All authors contributed toward data analysis, drafting and revising the paper and agree to be accountable for all aspects of the work.

\section{Disclosure}

The authors report no conflicts of interest in this work.

\section{References}

1. Signal TL, Paine SJ, Sweeney B, et al. The prevalence of symptoms of depression and anxiety, and the level of life stress and worry in new zealand māori and non-māori women in late pregnancy. Aust $N Z J$ Psychiatry. 2017;51(2):168-176.

2. Nagandla K, Nalliah S, Yin LK, et al. Prevalence and associated risk factors of depression, anxiety and stress in pregnancy. Int J Reproduction. 2016;5(7):2380-2388.

3. Nasreen HE, Kabir ZN, Forsell Y, Edhborg M. Prevalence and associated factors of depressive and anxiety symptoms during pregnancy: a population based study in rural Bangladesh. BMC Womens Health. 2011;11:22.

4. Karmaliani R, Asad N, Bann CM, et al. Prevalence of anxiety, depression and associated factors among pregnant women of Hyderabad, Pakistan. Int J Soc Psychiatry. 2009;55(5):414-424.

5. Al-Azri M, Al-Lawati I, Al-Kamyani R, et al. Prevalence and risk factors of antenatal depression among Omani women in a primary care setting: cross-sectional study. Sultan Qaboos Univ Med J. 2016; 16(1):e35-e41.

6. Alder J, Fink N, Bitzer J, Hösli I, Holzgreve W. Depression and anxiety during pregnancy: a risk factor for obstetric, fetal and neonatal outcome? A critical review of the literature. J Matern Fetal Neonatal Med. 2007;20(3):189-209.

7. Grote NK, Bridge JA, Gavin AR, Melville JL, Iyengar S, Katon WJ. A meta-analysis of depression during pregnancy and the risk of preterm birth, low birth weight, and intrauterine growth restriction. Arch Gen Psychiatry. 2010;67(10):1012-1024.

8. Grigoriadis S, VonderPorten EH, Mamisashvili L, et al. The impact of maternal depression during pregnancy on perinatal outcomes: a systematic review and meta-analysis. J Clin Psychiatry. 2013;74(4):e321-e341.

9. Ding $\mathrm{XX}, \mathrm{Wu} \mathrm{YL}, \mathrm{Xu} \mathrm{SJ}$, et al. Maternal anxiety during pregnancy and adverse birth outcomes: a systematic review and meta-analysis of prospective cohort studies. J Affect Disord. 2014;159:103-110.

10. Balaha M, Amr M, El-Gilany A, Al Sheikh F. Obstetric and psychiatric outcomes in a sample of Saudi teen-aged mothers. TAF Prev Med Bull. 2009;8(1):285-290.

11. Spielberger CD. Manual for the State-Trait Anxiety Inventory. Palo Alto, California: Consulting Psychologists Press; 1983.

12. Littleton HL, Breitkopf CR, Berenson AB. Correlates of anxiety symptoms during pregnancy and association with perinatal outcomes: a meta-analysis. Am J Obstet Gynecol. 2007;196(5):424-432.

13. Giardinelli L, Innocenti A, Benni L, et al. Depression and anxiety in perinatal period: prevalence and risk factors in an Italian sample. Arch Womens Ment Health. 2012;15(1):21-30. 
14. Nasreen HE, Kabir ZN, Forsell Y, Edhborg M. Low birth weight in offspring of women with depressive and anxiety symptoms during pregnancy: results from a population based study in Bangladesh. BMC Public Health. 2010;10:515.

15. Dayan J, Creveuil C, Herlicoviez M, et al. Role of anxiety and depression in the onset of spontaneous preterm labor. Am J Epidemiol. 2002; 155:293-301.

16. Cox JL, Holden JM, Sagovsky R. Detection of postnatal depression. Development of the 10-item Edinburgh Postnatal Depression Scale. Br J Psych. 1987;150:782-786.

17. Bunevicius A, Kusminskas L, Pop VJ, Pedersen CA, Bunevicius R. Screening for antenatal depression with the Edinburgh Depression Scale. J Psychosom Obstet Gynaecol. 2009;30:238-243.

18. Ghubash R, Abou-Saleh MT, Daradkeh TK. The validity of the Arabic Edinburgh Postnatal Depression Scale. Soc Psychiatry Psychiatr Epidemiol. 1997;32(8):474-476.

19. World Health Organization. The World Health Report 2001. Mental Health: New Hope, New Challenges. World Health Organization, Geneva; 2001. Available from: http://www.who.int/whr/2001/en/ whr01_en.pdf. Accessed March 2017.

20. Ustün TB, Ayuso-Mateos JL, Chatterji S, Mathers C, Murray CJ. Global burden of depressive disorders in the year 2000. Br J Psychiatry. 2004;184:386-392.

21. Murray CJ, Lopez AD. Alternative projections of mortality and disability by cause 1990-2020: Global Burden of Disease Study. Lancet. 1997;349(9064):1498-1504.

22. Amiel Castro RT, Pinard Anderman C, Glover V, O’Connor TG, Ehlert U, Kammerer M. Associated symptoms of depression: patterns of change during pregnancy. Arch Womens Ment Health. 2017;20(1):123-128.

23. Ross L, McLean M. Anxiety disorders during pregnancy and the postpartum period. A systematic review. J Clin Psychiatry. 2006;67: 1285-1298.
24. Andersson L, Sundström-Poromaa I, Wulff M, Astrom M, Bixo M. Neonatal outcome following maternal antenatal depression and anxiety: a population-based study. Am J Epidemiol. 2004;159(9): $872-881$.

25. Schetter CD, Tanner L. Anxiety, depression and stress in pregnancy: implications for mothers, children, research, and practice. Curr Opin Psychiatry. 2012;25(2):141-148.

26. Schetter CD. Psychological science on pregnancy: stress processes, biopsychosocial models and emerging research issues. Annu Rev Psychol. 2010;62:531-558.

27. Barker DJP, Erikson JG, Forsen T, Osmond C. Fetal origins of adult disease: strength of effects and biological basis. Int J Epidemiol. 2002; 31(6):11235-11239.

28. Thiagayson P, Krishnaswamy G, Lim ML, et al. Depression and anxiety in Singaporean high-risk pregnancies - prevalence and screening. Gen Hosp Psychiatry. 2013;35(2):112-116.

29. Peñacoba-Puente C, Carmona-Monge FJ, Marin-Morales D, Naber K. Coping strategies of Spanish pregnant women and their impact on anxiety and depression. Res Nurs Health. 2013;36(1):54-64.

30. Giardinelli L, Castellini G, Faravelli C, et al. Depression and anxiety in perinatal period: prevalence and risk factors in an Italian sample. Arch Womens Ment Health. 2012;15(1):21-30.

31. Ibanez G, Charles M, Forhan A, et al. Depression and anxiety in women during pregnancy and neonatal outcome: data from the EDEN motherchild cohort. Early Hum Dev. 2012;88(8):643-649.

32. Gawlik S, Waldeier L, Müller M, Szabo A, Sohn C, Reck C. Subclinical depressive symptoms during pregnancy and birth outcome-a pilot study in a healthy German sample. Arch Womens Ment Health. 2013; 16(2):93-100.

33. Chalana H, Sachdeva JK. A study of psychiatric morbidity during second trimester of pregnancy subsequent to abortion in the previous pregnancy. Asian J Psychiatr. 2012;5(3):215-221.
International Journal of Women's Health

\section{Publish your work in this journal}

The International Journal of Women's Health is an international, peerreviewed open-access journal publishing original research, reports, editorials, reviews and commentaries on all aspects of women's healthcare including gynecology, obstetrics, and breast cancer. The manuscript management system is completely online and includes

\section{Dovepress}

a very quick and fair peer-review system, which is all easy to use Visit http://www.dovepress.com/testimonials.php to read real quotes from published authors. 